\title{
'Choice, culture and confidence': key findings from the 2012 having a baby in Queensland Aboriginal and Torres Strait Islander survey
}

\author{
Susan Parker, Loretta McKinnon and Sue Kruske
}

\begin{abstract}
Background: To describe the maternity care experiences of Aboriginal and/or Torres Strait Islander women in Queensland, Australia and to identify areas for policy and practice improvements.

Methods: A culturally-tailored survey requesting both quantitative and qualitative information was completed by respondents either independently (online or in hard copy) or with the assistance of a trained peer-interviewer. Data were analysed using descriptive statistics and thematic analysis.

Eligible women were over 16 years of age, identified as Aboriginal and/or Torres Strait Islander, resided in Queensland, and had a live, singleton birth between the first of July 2011 and the first of July 2012.

Results: 187 women of 207 respondents were included in analyses. Women reported high rates of stressful life events in pregnancy, low levels of choice in place of birth and model of care and limited options to carry out cultural practices. High levels of confidence in parenting were also reported. Women were less likely to report being treated with kindness, understanding and respect by maternity care staff than women answering a similar mainstream survey.

Conclusions: Aboriginal and Torres Strait Islander women have additional needs to mainstream Australian women. This study identified a number of recommendations to improve services including the need to enhance the cultural competence of maternity services; increase access to continuity of midwifery care models, facilitate more choices in care, work with the strengths of Aboriginal and Torres Strait Islander women, families and communities, and engage women in the design and delivery of care.
\end{abstract}

Keywords: Birthing on country, Indigenous, Aboriginal, Torres Strait Islander, Maternity care

\section{Background}

Aboriginal and/or Torres Strait Islander ${ }^{1}$ women have a higher prevalence of factors associated with negative health outcomes for mothers and newborns compared to their non-Indigenous counterparts [1-5]. Aboriginal and/or Torres Strait Islander women are also at risk of not receiving culturally tailored care during the maternity period [6-8] and have frequently reported dissatisfaction with hospital-based maternity care experiences [9-11]. Birthing is often considered a fearful time for many women, regardless of ethnicity [12]. For Aboriginal and/or Torres Strait Islander women this experience can

\footnotetext{
*Correspondence: s.kruske@uq.edu.au

Queensland Centre for Mothers \& Babies, The University of Queensland, Brisbane, Australia
}

be even more difficult because of the lack of culturally competent mainstream systems [7], previous negative experiences with the health care system, and a high burden of disease [13]. In addition, higher proportions of Aboriginal and/or Torres Strait Islander women are required to leave their communities and relocate for birth resulting in birthing without support people, worrying about their children left behind and suffering logistical and financial burdens related to travelling $[14,15]$. Aboriginal and/or Torres Strait Islander women are often subject to a broad range of life stressors such premature and unexpected death of family members, financial stress, family violence and socio-economic disadvantage [5,16-18]. Finally, many Aboriginal and/or Torres Strait Islander women and families continue to suffer the impact of 
racism, colonisation and the stolen generation, which can result in fear and distrust of government services and the hospital environments [7].

Many of the directions of current Queensland [19] and National [20] policy documents support improvements in maternity care available to Australian women with specific attention given to Aboriginal and/or Torres Strait Islander women. In particular, these reforms aim to enhance consumer involvement and choice in relation to maternity care and to ensure that quality, evidencebased, safe and culturally competent care is delivered by an appropriately trained workforce within a sustainable maternity care system $[19,20]$.

Obtaining consumer input is critical for the design, implementation, and evaluation of maternity care services [21]. Published work around the maternity experiences of Aboriginal and Torres Strait Islander women in Queensland is limited [22,23]. This study aimed to explore the maternity care experience of Aboriginal and/or Torres Strait Islander women birthing in Queensland using mixed methods and peer interviewer techniques previously not utilised in this area of research. Both quantitative and qualitative data were assessed to determine opportunities for improving the delivery of maternity care services to this population.

\section{Methods}

\section{Research design}

The research design involved the construction of a culturally tailored data collection instrument and selection of sample recruitment and data collection methods designed to maximise representation and access to Aboriginal and/or Torres Strait Islander women.

\section{Geographic sample selection}

A stratified, purposeful sampling technique was used to ensure a diverse geographical sample of participants. Six areas across Queensland were chosen for their high number of Aboriginal and/or Torres Strait Islander births and to reflect a mix of urban, regional and remote dwelling women. These were: Brisbane; Townsville/Palm Island; Mount Isa (including Doomadgee and Mornington Island); Thursday Island; Rockhampton; and Woorabinda.

\section{Data collection instrument}

The survey [24] was adapted from the mainstream 2012 Having a Baby in Queensland (HABIQ) survey [25] to improve cultural relevance to Aboriginal and/or Torres Strait Islander women's maternity care experience. Modifications from the mainstream survey included the changing of wording to improve readability and meaning for an Aboriginal and or Torres Strait Islander audience. Additional items were added to capture experiences known to impact on Aboriginal and Torres Strait Islander women.
These included stressful events in pregnancy, specific cultural practices and experiencing racism through items that elicited feeling judged, being talked down to and being treated as an individual.

The 24 page survey was adjusted based on a pilot study that tested the suitability and readability of the tool with five Aboriginal women who had recently had a baby outside of Queensland and were known to the Aboriginal researcher on the team. Women were asked about the quality of care received during pregnancy, labour and birth and postnatal periods and were invited to provide comments on suggested improvements to care. Demographic characteristics were also collected.

Some survey items required respondents to select from a number of pre-determined responses (including likert scales). For example, respondents were asked the question "Where was your baby born?" with response options including 'public hospital', 'private hospital,' 'birth centre,' 'at home,' 'not sure' or 'other'. Data derived from these questions are described through this paper as 'quantitative' data. Other questions in the survey requested an openended response, where respondents could provide what they felt was the relevant detail without any limitation with regard to the topics they could raise. An example of such an open-text question was "What were the good things about your pregnancy care?". Throughout this paper, data collected from these type of open-ended questions are described as 'qualitative' data.

\section{Sample selection and recruitment}

Aboriginal and/or Torres Strait Islander women who had a live singleton birth in Queensland between I July 2011 and 1 July 2012 were invited to participate. The age requirement was 16 to ensure that respondents were of an age where they could consent and so that young mothers were not excluded from participating. Consistent with other studies investigating the health experiences of Aboriginal and/or Torres Strait Islander populations [26], multiple methods were used to recruit participants. The study was promoted via social media (including facebook and twitter), through posters in, maternity services, community hubs (e.g. Aboriginal Community Controlled Health Organisations) and using stalls at local events (e.g. National Aboriginal and Islander Day of Commemoration (NAIDOC). Consent to contact forms were available at the places for women to indicate their interest in participating.

Peer interviewers were recruited to administer the survey across the six designated project sites and were supported by the Aboriginal project lead (first author). They were local Aboriginal and/or Torres Strait Islander women wellconnected to their community with good verbal and written communication skills. Use of peer interviewers was to enhance the engagement of a broad range of Aboriginal and/or Torres Strait Islander women and to 
facilitate interviews being conducted in a sensitive and culturally appropriate manner (thus enhancing the quality of the data collected). In total, 28 peer interviewers (age range: 20 to 60) were recruited across the project sites. To allow greater flexibility and reduced monitoring and recording of hours worked, peer interviewers were paid per survey completed, rather than per hour.

Training was provided to all of peer interviewers to ensure that they understood the project objectives, their role in the project, and how to follow research procedures such as gaining consent, data collection and storage. The training also focused on the development of practical skills such as how to recruit participants to do the survey, learning interview skills and what action to take when women needed to access further support from appropriate health professionals. Peer interviewers were actively involved in promoting the survey, and recruiting participants from their own informal networks.

\section{Data collection and analysis}

Data collection occurred between July and October 2012. Women could complete the survey either online or using a hard copy, or by either method with the assistance of a peer-interviewer. Data collected via peer interviewers varied with most interviews conducted at the participant's home or in cafes. A total of 169 (90\%) women used peer interviewers to complete the survey and 18 (10\%) completed the survey individually. A number of peer interviewers had their laptops and internet connection and were able to enter the information directly while they conducted the survey. Only two peer interviewers completed surveys in this way with the remainder using hard copy survey forms. Thirty one surveys were completed on line (including those by peer interviewers) with the remainder being completed on hardcopy.

The quantitative analysis involved the generation of descriptive statistics using SPSS (version 21). The qualitative data were subject to a thematic analysis undertaken by the first and second authors. NVivo (version 9) was used for these analyses. Data familiarisation was undertaken whereby the researchers read and re-read the data to become familiar with the content. The data were then systematically assessed for the identification of ideas, meanings, concepts and keywords and relevant 'codes' were developed. These codes were then compared and contrasted, and similar concepts were grouped into themes.

Each researcher independently assessed a number of open-text survey questions. Formal double-coding was not undertaken. However, the authors regularly met and discussed the decisions being made with regard to the coding of data and the development of themes. This collaborative analysis is likely to have enhanced the trustworthiness of the findings. Illustrative quotes are provided in the results section to further support the rigour of the analysis and the authenticity of the themes derived.

\section{Ethics}

The study was approved by the Human Research Ethics Committee of the School of Psychology, University of Queensland. Written consent was obtained by peer interviewers following reading out the information sheet and prior to completing the survey. Consent was obtained from women filling out the survey on line through the process of clicking on the 'I Consent' button at the bottom of the information statement prior to progressing to the survey instrument.

\section{Results}

\section{Participant characteristics}

Demographic characteristics of the women are presented in Table One. A total of 187 women of 207 respondents were included in analyses. This represents approximately $5 \%$ of the 3649 Aboriginal and/or Torres Strait Islander women who birthed in Queensland in 2011 [27].

The sample was representative of Aboriginal and/or Torres Strait Islander women in Australia in terms of location, parity and age characteristics [28]. A higher proportion of women in the sample identified of being of Torres Strait Islander descent (9.6\%) or of both Aboriginal and/or Torres Strait Islander decent (19.3\%) compared to the total Australian population (respectively $6 \%$ and $4 \%)$ [29]. The sample was more educated that the overall Indigenous population with $10.2 \%$ of respondents indicating that they had completed tertiary studies, compared to the national average of $5.0 \%$ for Indigenous Australians [30]. This observation is consistent with known research participation patterns wherein generally higher proportions of educated or affluent persons participate in research compared to those who are less advantaged [31] Table 1.

\section{Antenatal service delivery}

The survey investigated a number of aspects of antenatal care including the timing, number and experience of antenatal appointments.

\section{Timing of first antenatal visit}

Survey respondents first saw a health professional regarding their pregnancy at an average gestation of 7.9 weeks (SD 3.71 weeks; range 2 to 28 weeks).

\section{Number of check-ups while pregnant}

A minimum number of five antenatal appointments is a national performance indicator [2] due to its association with improved outcomes [32]. Approximately two thirds of women ( $n$ 126, 67.4\%) attended at least five antenatal appointments. The remaining women attended either 
Table 1 Participant characteristics $(n=187)$

\begin{tabular}{|c|c|c|}
\hline & $\%$ & (n) \\
\hline \multicolumn{3}{|l|}{ Indigenous status (self-reported) } \\
\hline Aboriginal & 71.1 & (133) \\
\hline Torres Strait Islander (TSI) & 9.6 & $(18)$ \\
\hline Both Aboriginal and TSI & 19.3 & (36) \\
\hline \multicolumn{3}{|l|}{ Age (at time of birth) } \\
\hline $16-24$ & 52.9 & (99) \\
\hline $25-29$ & 23.0 & $(43)$ \\
\hline $30-39$ & 23.0 & $(43)$ \\
\hline$>40$ & 1.1 & (2) \\
\hline \multicolumn{3}{|c|}{ Education (highest level completed) } \\
\hline Did not complete primary school & 0.5 & (1) \\
\hline Primary school & 5.3 & $(10)$ \\
\hline Year 10 or equivalent & 44.9 & $(84)$ \\
\hline Year 12 or equivalent & 34.8 & $(65)$ \\
\hline Trade/apprenticeship & 4.3 & (8) \\
\hline Tertiary qualifications & 10.2 & $(19)$ \\
\hline \multicolumn{3}{|l|}{ Area of residence ${ }^{b}$} \\
\hline Major cities & 34 & $(64)$ \\
\hline Outer regional & 44 & $(83)$ \\
\hline Remote and very remote & 20 & $(38)$ \\
\hline \multicolumn{3}{|l|}{ Have other children ${ }^{a}$} \\
\hline Yes & 63.1 & (118) \\
\hline No & 35.8 & (67) \\
\hline
\end{tabular}

a: This description is used rather than parity as women were not asked about the number of times they had previously given birth, rather they were asked whether or not they had other children.

b: based on the Accessibility and Remoteness Index of Australia.

one ( $n 2,1.0 \%)$, two ( $n 8,4.3 \%)$, three $(n 14,7.5 \%)$, or four ( $n 19,10.2 \%)$ appointments, or did not provide data for this question ( $n 18,9.6 \%)$.

\section{Choice of gender of health care provider}

Women were asked whether they could choose between male or female care providers during pregnancy. The response options were 'Yes,' 'No', and 'Unsure'. Over one third of women responded that they could not choose their care provider's gender ( $n 69,36.9 \%$ ) or were unsure whether a choice was available ( $n 64,34.2 \%)$. The remaining women indicated that they could choose the gender of their care provider ( $n 52,27.8 \%$ ).

\section{Acceptability of questions about particular health topics during the antenatal period}

Women were asked how comfortable they felt being asked routine questions on a range of issues by their health professional. Approximately ten percent of women (n 19, $10.2 \%)$ indicated that they felt uncomfortable when asked about various issues by health professionals during their pregnancy. Among the topics that made women feel uncomfortable, smoking cigarettes, use of other drugs, and domestic violence were the most commonly mentioned topics (see Figure 1).

\section{Stressful life events during pregnancy}

The majority of women indicated that they had experienced at least one stressful life event during their pregnancy ( $n$ 116, 62\%). Such stressful life events included moving house, financial stress or a death in the family. The proportion of the sample experiencing each type of stressful life event is shown in Figure 2.

\section{Birthing and hospital stay}

The majority of women ( $n$ 183, 97.3\%) birthed in a public hospital, with the remainder of women birthing either in a birth centre $(n 3,1.6 \%)$ or at home $(n 1,0.5 \%)$. Two thirds of women ( $n 123,66 \%)$ indicated that they did not have a choice as to where they could have their baby. Two thirds of women indicated that an Indigenous specific service was available to them however, only half of women with access to such a service chose to use it.

Women were asked "Were you able to carry out any cultural practices during your pregnancy and birth?". Very few women ( $n$ 24, 12.8\%) indicated that they were able to carry out any cultural practices during their pregnancy and birth. A number of women made comments to indicate that they did not realise that engaging in cultural practices within the hospital setting was an option available to them since an invitation to participate in such practices was not made by hospital staff.

"I didn't ask, I just presumed that I would not be able to do this in the hospital" (Respondent 48, Inner regional, had other children)

Some, but not all, maternity staff, were perceived as being supportive of women engaging in cultural practices surrounding birth.

"If I wanted to I don't think there would have been an issue" (Respondent 79, Major city, had other children)

"Doctors told me I could not take my placenta out of surgical room due to contamination" (Respondent 144, Major city, had other children)

\section{Post natal experiences}

Women were asked to report how confident they felt in looking after their baby once they had returned home. Women's responses were: 'extremely confident' ( $n$ 97, $52 \%$ ), 'fairly confident' ( $n$ 47, 25\%), 'confident' (n 26, 14\%), 'not very confident' ( $n$ 9, 5\%), 'my baby hasn't come yet' ( $n$ 2, 1\%) and missing data $(n 4,2 \%)$. When parity was 


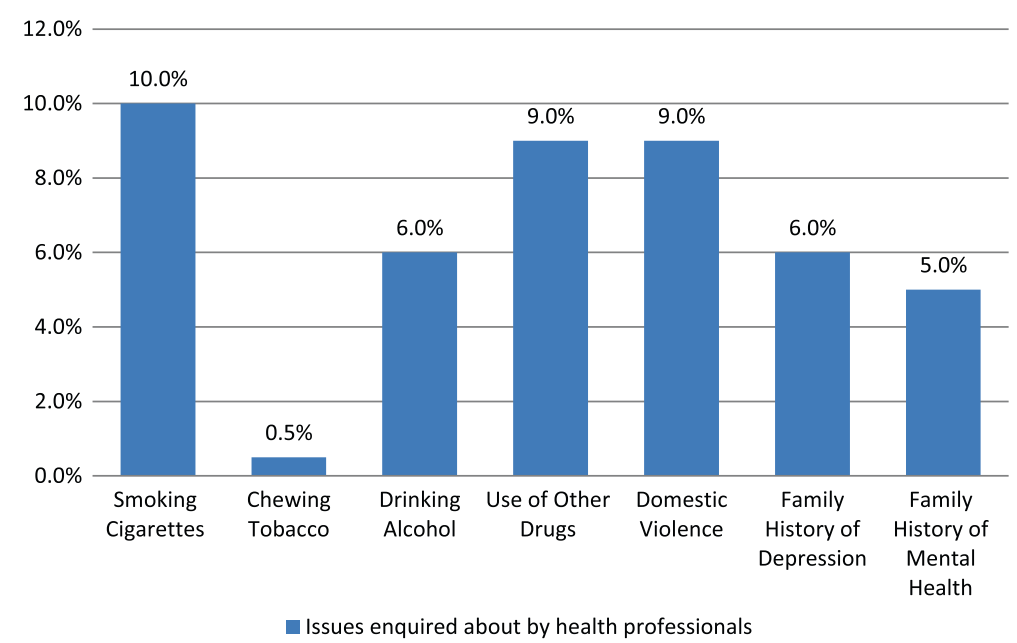

Figure 1 Proportion of women who felt uncomfortable being asked about various topics.

considered, as expected, multiparous (who reported having other children) women were more confident caring for their baby when they returned home. Specifically, $63.6 \%$ ( $n$ 75) of multiparous women reported being 'extremely confident' compared to $35.8 \%$ (n 24) of women having their first baby.

Approximately a quarter of the women interviewed indicated that they did not feel that they had anyone to talk to with regards to how they were feeling after the birth of their baby ( $n 50,27 \%)$. An equally low number of women $(n$ 33, 18\%) indicated that they had joined a mothers and babies group in their local area.

\section{Maternity care service delivery overall Continuity of carer during pregnancy}

The majority of women ( $n$ 136, 72.7\%) indicated that they saw the same health professional during their pregnancy. Throughout the survey, when women were asked to articulate the positive aspects of their care, women commented on their satisfaction with having a known midwife or the same midwife during their pregnancy. The quote below is exemplary regarding the type of comments women made about the way that care from a known provider enhanced their maternity care experience.

"Having the same midwife \& her personal contact details to call anytime" (Respondent 8, Major city, had other children).

\section{Relocating for birth}

Just under one third of women left their community in order to give birth ( $n 53,28.3 \%)$. All lived in an outer regional, remote, or very remote community. Almost all of these women had a support person ( $n 45,85 \%)$ however, 15.1\% ( $n$ 8) did not. Most of those who travelled with a support person ( $n 31,69.0 \%$ ), indicated that their support person did not receive any financial assistance to accompany them when travelling to give birth.

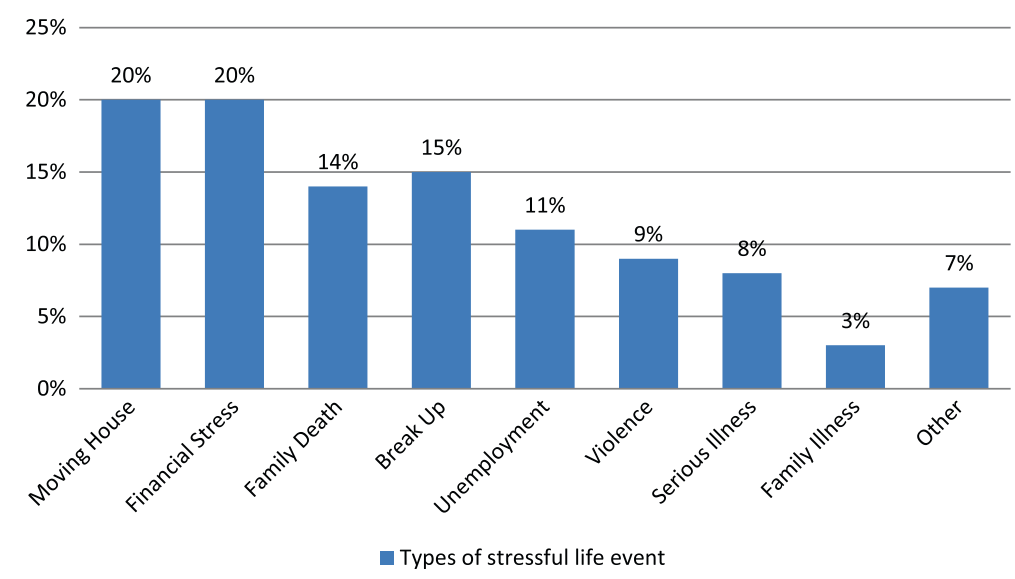

Figure 2 Proportion of women experiencing various stressful life events during pregnancy. 
Among women who travelled for birth the majority of women ( $n$ 32, 60.0\%) indicated that they would have preferred to stay in their own community to give birth. These women described issues associated with childcare, interruption to their partner's work in order to travel, feelings of isolation from not having partner or family there with them and a lack of adequate financial assistance for travel and accommodation. Below are some illustrative quotes from women who indicated that they would have preferred to stay in their community to give birth.

"It would have saved a lot of hassle and money"

(Respondent 126, Remote location, had other children)

"It would have been a lot easier as my eldest is school age $\mathcal{E}$ it's hard to go away for a whole month"

(Respondent 7, Inner regional, had other children)

\section{Interpersonal aspects of care}

Women were asked about a number of interpersonal aspects of their care during pregnancy, labour, birth and during the postnatal period. Specifically, women were asked how often they were: treated as an individual; treated with kindness and understanding: not 'talked down to'; and not 'ignored' by health staff. The response options were 'always', 'often,' 'sometimes,' 'rarely,' 'never,' or 'prefer not to say'. The proportions of women who indicated how often they were treated in each of the manners addressed are presented in Table 2 with the most popular response for each question shown shaded. As can be seen in Table 2, just over half of the women (more than 59\%) indicated that throughout their care they were always treated with respect, as an individual or with kindness and understanding.

The qualitative analysis yielded further information on what women thought were the 'good' and 'not so good' aspects of their care during pregnancy. Women described 'good' aspects of their care as seeing the same person, or a familiar person throughout their care.

"Having the same midwife help guide me through each stages of my pregnancy. The midwife was with me also during my doctors' appointments which was a big help, as they knew the right questions to ask..." Respondent 110, urban location, primparous.

The comments of women also reflected how the expression of empathy and kindness by caregivers enhanced their experience. The 'not so good things' reported by women included long wait times, not being able to be seen by the same doctor or midwife, rude staff and costs associated with travelling and maternity care.

"Waiting for ages in the waiting room. One time I waited for an hr and a half because the midwife took the wrong slip." Respondent 165, remote location, primiparous.

\section{Transport}

Women were asked what mode of travel they used to attend most of their pregnancy check-ups. The response options were: 'walked'; 'drove own car'; 'got lift from partner, friends or family'; 'health care worker picked me up'; 'public transport (e.g. bus, train)'; or 'other'. Women could report using as many modes of transport as were applicable, however most women reported using a single mode of transport ( $n$ 150, 80\%). The type of transport used by these women who used a single mode are shown in Figure 3. Among those who used multiple forms of transport ( $n$ 32, 16.6\%), most got a lift from a partner friend or family member $(n 24,72.7 \%)$ in addition to walking, driving themselves or public transport.

\section{Discussion}

This study explored Aboriginal and/or Torres Strait Islander women's perceptions of care during pregnancy, labour, birth and the postnatal period. Aboriginal and/or Torres Strait Islander women's satisfaction with maternity care has been measured in a number of previous studies [22,23,33-35].

\section{Antenatal care}

The average time at which women first saw a health professional in their pregnancy was 7.9 weeks (SD 3.71; range 2 to 28 weeks). Whilst this represents an earlier timeframe outlined in a recent paper which found the average time of first prenatal visit for Aboriginal women in South Australia as 10.1 weeks (SD 4.8) [26]. It is, however, similar to the average time of first visit among all women in the HABIQ 2012 sample [25] that reported an average of 8.0 weeks gestation (SD 3.90; range 0 to 32 weeks).

Increasing access to quality antenatal care for Aboriginal and/or Torres Strait Islander women has been noted as an important goal by a number of authors [22,36,37] and changes to antenatal care delivery has been found to increase service use by this population in some parts of Queensland [37]. Three factors associated with increased participation in antenatal care identified by Ship et al. include: awareness of community services, attendance at childbirth education classes and interest from father and extended family [38].

\section{Postnatal care}

The participants in this survey indicated a lack of postnatal support with high proportions of women (63\%) indicating that they had no-one to talk to about how they were feeling after the birth of their baby and/or who had not joined a local mothers group (76\%). These findings support other calls to ensure Aboriginal and/or Torres 
Table 2 Women's evaluation of five components of communication with hospital staff during three time periods* A During your labour and birth did you feel like the health professionals or other staff:

\begin{tabular}{|c|c|c|c|c|c|c|c|c|c|c|}
\hline & \multicolumn{2}{|c|}{$\begin{array}{l}\text { Treated you with } \\
\text { respect }\end{array}$} & \multicolumn{2}{|c|}{$\begin{array}{l}\text { Treated you as an } \\
\text { individual }\end{array}$} & \multicolumn{2}{|c|}{$\begin{array}{l}\text { Treated you with kindness } \\
\text { and understanding }\end{array}$} & \multicolumn{2}{|c|}{ Talked down to you } & \multicolumn{2}{|c|}{$\begin{array}{l}\text { Judged, insulted or } \\
\text { ignored you }\end{array}$} \\
\hline & $\%$ & (n) & $\%$ & (n) & $\%$ & (n) & $\%$ & (n) & $\%$ & (n) \\
\hline Always & 68 & (128) & 61 & (114) & 64 & (119) & 3 & (6) & 3 & (5) \\
\hline Often & 16 & (29) & 15 & $(28)$ & 17 & (32) & 3 & (6) & 5 & (9) \\
\hline Sometimes & 10 & (19) & 11 & (20) & 13 & (24) & 10 & (18) & 8 & $(15)$ \\
\hline Rarely & 1 & $(2)$ & 3 & (6) & 2 & (3) & 9 & $(16)$ & 5 & $(10)$ \\
\hline Never & 2 & (3) & 5 & (10) & 2 & (3) & 71 & (132) & 75 & $(140)$ \\
\hline
\end{tabular}

B After giving birth while you were still in hospital did you feel like the health professionals or other staff:

Treated you with respect Treated you as an individual Treated you with kindness Talked down to you Judged, insulted or

\begin{tabular}{|c|c|c|c|c|c|c|c|c|c|c|}
\hline & \multirow[b]{2}{*}{$\%$} & \multirow[b]{2}{*}{ (n) } & \multirow[b]{2}{*}{$\%$} & \multirow[b]{2}{*}{ (n) } & \multicolumn{2}{|c|}{ and understanding } & \multirow[b]{2}{*}{$\%$} & \multirow[b]{2}{*}{ (n) } & \multicolumn{2}{|c|}{ ignored you } \\
\hline & & & & & $\%$ & (n) & & & $\%$ & (n) \\
\hline Always & 68 & (128) & 59 & (111) & 69 & (129) & 3 & (5) & 2 & (3) \\
\hline Often & 14 & (26) & 15 & (28) & 15 & (28) & 2 & (4) & 2 & (4) \\
\hline Sometimes & 10 & (19) & 13 & (24) & 10 & (19) & 9 & (16) & 9 & (16) \\
\hline Rarely & 2 & (3) & 2 & (3) & 1 & (2) & 9 & (17) & 9 & (17) \\
\hline Never & 0 & (0) & 5 & (10) & 0.5 & (1) & 70 & (131) & 71 & (133) \\
\hline
\end{tabular}

C After giving birth when you returned home did you feel like the health professionals or other staff:

\begin{tabular}{|c|c|c|c|c|c|c|c|c|c|c|}
\hline & \multicolumn{2}{|c|}{$\begin{array}{l}\text { Treated you with } \\
\text { respect }\end{array}$} & \multicolumn{2}{|c|}{$\begin{array}{l}\text { Treated you as an } \\
\text { individual }\end{array}$} & \multicolumn{2}{|c|}{$\begin{array}{l}\text { Treated you with kindness } \\
\text { and understanding }\end{array}$} & \multicolumn{2}{|c|}{ Talked down to you } & \multicolumn{2}{|c|}{$\begin{array}{l}\text { Judged, insulted or } \\
\text { ignored you }\end{array}$} \\
\hline & $\%$ & $(n)$ & $\%$ & $(n)$ & $\%$ & (n) & $\%$ & (n) & $\%$ & (n) \\
\hline Always & 68 & (128) & 61 & (114) & 70 & $(130)$ & (3) & 5 & 3 & (6) \\
\hline Often & 18 & (33) & 18 & (33) & 19 & $(36)$ & (3) & 5 & 2 & (4) \\
\hline Sometimes & 6 & $(11)$ & 6 & $(12)$ & 2 & (4) & (3) & 5 & 2 & (3) \\
\hline Rarely & 1 & $(2)$ & 2 & (3) & 1 & $(2)$ & $(12)$ & 22 & 8 & (15) \\
\hline Never & 0.5 & (1) & 6 & (12) & 2 & (3) & (72) & 136 & 78 & (145) \\
\hline
\end{tabular}

Strait Islander women have access to quality care and support during pregnancy, birth and the postnatal period $[5,39]$. Significant investment into strengthening Indigenous maternal and child health services has occurred across Australia in recent years through programs such as the New Directions: Mothers and Babies Services [40], Healthy for Life [41] and Australian Nurse Family Partnership [42]. Effectiveness of these programs on Aboriginal and Torres Strait Islander women and babies outcomes is not well captured [40].

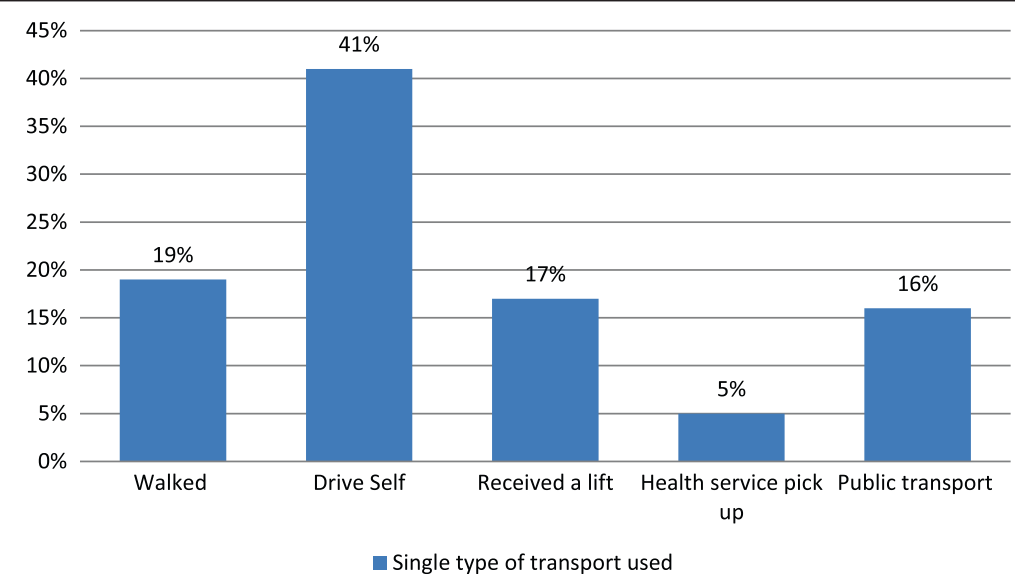

Figure 3 Distribution of the types of transport used to attend appointments during pregnancy. 


\section{Feeling respected}

Women were asked about a number of interpersonal aspects of their care during pregnancy, labour, birth and during the postnatal period. Over half of the women $(\leq 59 \%)$ expressed satisfaction with care, with approximately 30\% indicating that they were not 'always' treated as an individual, treated with kindness and understanding, not 'talked down to', and not ignored, by medical staff. Woman-centred care is a current national maternity reform objective [20] and has been defined as:

'a process in which a woman makes choices and is involved in and has control over her care...' [43].

The results of this study imply that for a considerable number of women a central tenet of women-centred care, being respected, may not be being met.

Dietsch and colleagues [44] reported that Aboriginal women were being more likely to be treated poorly by maternity staff, describing experiences that were interpreted as bullying. Approximately $70 \%$ in our study reported 'always' being treated with respect or not being talked down to. This raises issues for the remaining 30\% women who indicated an alternative experience.

Differences for Aboriginal and/or Torres Strait Islander women compared to mainstream women can be found in the higher proportions of women in the mainstream HABIQ 2012 study [25], who reported 'always' being treated with respect (76.7\% vs $68 \%)$, treated as an individual (75.4\% vs 61\%), and treated with kindness and understanding (75.7\% vs $64 \%)$ [25].

\section{Choices in maternity care}

The lack of choices available to Aboriginal and/or Torres Strait Islander women has been documented in a number of publications and reports [15,45-48]. The type of choices advocated for include the geographical location of birth [48], model of care received [33,36], choice of who is present at the birth and whether culturally important protocols are adhered to [15]. This study collected data relevant to maternity care choices including whether women had a choice of male or female care providers during their pregnancy, whether women would have preferred to stay in their local community to give birth, the place of birth, and whether continuity of care was available.

Over two thirds of women (71.1\%) indicated that they were either not able, or were unsure whether they were able, to choose the gender of their care provider during pregnancy. Many Aboriginal and/or Torres Strait Islander women have cultural beliefs regarding gender roles and participation during the maternity period and have reported feelings of 'shame' in being cared for in birth by men [15] and when discussing reproductive health issues in general [49]. Therefore, not having a choice in the gender of caregivers could cause distress for some Aboriginal and/ or Torres Strait Islander women.

Sixty percent of women who relocated to give birth indicated that, given the choice, they would have stayed in their local community to give birth. Results also suggest that women may have had a limited choice of birthing venues since the majority of women surveyed birthed in public hospitals $(97.3 \%)$, with very few women birthing in birth centres $(1.6 \%)$ or at home $(0.5 \%)$. This assertion that there was a lack of choice in venue was supported by the majority of women (66\%) expressing that they did not have a choice in terms of where they gave birth.

A number of authors indicate that choice is limited for many Aboriginal and/or Torres Strait Islander women with the focus of existing maternity care delivery being on bio-physical safety, with the provision of culturally safe care being a lower priority $[6,15,48]$. The provision of choices in maternity care for all Australian women is a goal of Queensland specific and national maternity care reforms $[19,20]$ and should be prioritised for this population.

\section{Cultural practices in childbirth}

Only a small proportion of women indicated that they were able to carry out any cultural practices during their pregnancy and birth (12.8\%). When asked whether they carried out any cultural practices a number of women mentioned that they were not invited to carry out any cultural practices by maternity care staff. This may suggest that without being asked, Aboriginal and/or Torres Strait Islander women may have felt that they could not engage in cultural practices.

\section{Travelling for birth}

Other studies $[11,35]$ have reported women's' feelings of loneliness and fear, due to being sent away from their own communities for birth. These findings were also supported by women in this current study who indicated that travelling away for birth caused additional stress. Travelling in order to give birth has been reported as being both socially and emotionally taxing for Aboriginal and/or Torres Strait Islander women $[15,33,48]$. Poverty, and or inadequate financial resources has been noted as an additional stressor for Indigenous women travelling to give birth both in Canada [48,50] and Australia [17,51]. Aboriginal and/or Torres Strait Islander women relocating for birth incur expenses including, their own travel and accommodation costs and those of their support person $[22,52]$. They may also incur childcare costs for children that are left at home. This study particularly highlighted the inadequacy of financial subsidies, and resulting stress for women who were required to travel 
to give birth whom comprised nearly one third of the women sampled (28.3\%).

\section{Recommendations for policy and practice}

A number of opportunities to improve women's experiences of care were identified. These include the need to: enhance the cultural competence of maternity services; improve access to continuity of midwifery care models; facilitate more choices in care; and, work with the strengths of Aboriginal and Torres Strait Islander women, families and communities.

\section{Culturally competent care}

Internationally it has been acknowledged that women's perceptions and needs during childbirth are socio-culturally defined [53]. Several Australian publications have emphasised the limitations of maternity services in recognising this $[7,15,33,54]$. Cultural competence has been defined in terms of the characteristics of organisations and individuals as:

\section{"Organisations [that] have a defined set of values and principles, and demonstrate behaviours, attitudes, policies and structures that enable them to work effectively cross-culturally. Cultural competence is a developmental process that evolves over an extended period. Both individuals and organisations are at various levels of awareness, knowledge and skills along the cultural competence continuum". [55]}

A lack of culturally appropriate care can result in shame for women and avoidance of the health system $[15,33,37]$. Providing culturally competent care is likely to improve health outcomes of Aboriginal and/or Torres Strait Islander women and their babies by increasing their use of maternity care services [56,57]. Care providers should be especially mindful of the high risk of this population to be subject to multiple life stressors including, commencing childbearing at a relatively young age [58] and being of low socioeconomic position $[17,18]$. The impact of many such known stressors for Aboriginal and/or Torres Strait Islander persons were demonstrated in the findings of this research, including moving house, financial stress, and exposure to violence [30,59]. Thus, this research reinforces the need for staff providing maternity care services to Aboriginal and/or Torres Strait Islander women to be aware of the additional life-stressors faced by this population that may impact on their health and coping during the maternity period.

Improving the education of the workforce specifically in terms of the provision of culturally competent care is highlighted as a state-wide [19] and national [20] reform objective. This study provides further support for the importance of these goals. Reports have been prepared specifically to assist with guiding the provision of culturally competent care to Aboriginal and/or Torres Strait Islander Australians and these should be consulted to optimally pursue this goal $[7,22,60]$.

\section{Continuity of midwifery care}

Aboriginal and/or Torres Strait Islander women have been reported positive experiences where care is received by a primary or small group of midwives, allowing women to develop trust through continuity of care [33,61]. While continuity of care across the full child care continuum (pregnancy, labour and post natal care) was not collected in this study, $72.7 \%$ indicated that they saw the same health professional during their pregnancy. Qualitative comments indicated that knowing their midwife was highly valued by women and supports the findings by Josif et al. [33].

Given that a high proportion of women (28.0\%) travelled to give birth, continuity of care may need to be assessed differently for this group. In some Australian regions continuity of care from a known midwife is being successfully implemented for Aboriginal women living in remote areas $[33,45,62]$ as well urban areas $[34,63]$. Recent Australian evidence suggests that midwifery-led continuity of care models are safe, cost effective [64] and are highly desired by women [33,65-67]. The opportunity for continuity of care is promoted as a national maternity reform objective as is providing choices of care to women in a range of settings, including rural settings where a disproportionately high number of Indigenous women are located [20].

\section{Working with strengths of women and community}

This study found higher levels of confidence in parenting compared to Queensland women responding to the same questions in a mainstream survey in 2012 [22]. Irrespective of parity, a higher proportion of Aboriginal and/or Torres Strait Islander women reported the highest level of confidence ('extremely confident') in caring for their baby upon returning home (multiparous 63.6\%, and primiparous $35.8 \%$ ) compared to women in the 2012 HABIQ overall population study (multiparous $47.0 \%$, and primiparous 10.6\%) [25].

Although Aboriginal and/or Torres Strait Islander women experience greater risk factors [1-5] and suffer higher exposure to stressful life events [16-18] (which were supported by our findings), there are many strengths in these families that are often overlooked and underutilised by health service providers.

Confidence in parenting is one example of a strength that should not be overlooked. Family support, connection to country and cultural identify are other examples reported in the literature [68-73] but were not assessed in this current study. 
While a strengths-based approach is promoted in the literature [74] this is often difficult to achieve given the different focus on risk between the health system and some women [6]. More effort by the maternity sector to work with women and community strengths should result in more engagement by women, higher compliance and better outcomes $[69,73,75]$.

\section{Engaging women in the design and delivery of service}

It is widely acknowledged that ensuring Aboriginal and/ or Torres Strait Islander Australians governance and ownership regarding Indigenous maternity care delivery is likely to enhance maternity care satisfaction for this population $[36,54,76]$. Accessing women's experiences is an important component of the engagement of women in the design and delivery of services. This survey demonstrates an effective strategy for achieving this. Additional strategies identified in the literature include: working with community elders and cultural knowledge brokers to ensure two way learning and knowledge in the delivery of care; the establishment of Aboriginal and/or Torres Strait Islander Advisory Groups; shared governance structures across mainstream and Indigenous agencies; family involvement and; the inclusion of Aboriginal and/or Torres Strait Islander personnel, especially female staff $[45,77,78]$.

\section{Limitations and strengths of this study}

The observational nature of this study does not allow conclusions about causality to be drawn from the data. The survey did not attempt to capture clinical data, nor did it measure a number of lifestyle factors known to contribute to poor perinatal health outcomes in Indigenous populations. These data are available elsewhere [79-81] and were not the focus of this study. Rather, the focus of this study was to investigate how maternity care was evaluated by Aboriginal and/or Torres Strait Islander women to inform improvements in service delivery. Although the responses represented only $5 \%$ of the Aboriginal and/or Torres Strait Islander births in 2011, it was representative in geographical location with good participation from remote and very remote dwelling women. Other strengths include the focus on women's perceptions of maternity care services, the use of a culturally appropriate research design using peer interviewers and the application of mixed-methods.

Another unexpected limitation was the lack of qualitative information recorded by some interviewers. Remuneration for peer interviewers was per survey, rather than per hours worked. This was to increase flexibility for the peer interviewers and reduce the need for monitoring and recording of hours worked. This model could have been a disincentive for peer interviewers to encourage the women to talk more about their experiences, or record these conversations as qualitative data.

\section{Conclusion}

This paper has provided some important insights into maternity care provision by accessing and reporting on the voices of birthing Aboriginal and/or Torres Strait Islander women in Queensland. Women reported high rates of stressful life events in pregnancy, low levels of choice in place of birth and model of care and limited options to carry out cultural practices. High levels of confidence in parenting were also reported. These findings indicate that Aboriginal and/or Torres Strait Islander women require specific and considered care that addresses their unique cultural, social and historical place in Australian society. Recommendations to improve women's experiences of care include the need to: enhance the cultural competence of maternity services; improve access to continuity of midwifery care models; facilitate more choices in care; and, work with the strengths of Aboriginal and Torres Strait Islander women, families and communities.

\section{Competing interests}

The authors declare that they have no competing interests.

\section{Authors' contributions}

SP designed the survey, analysed the data and revised the manuscript. L McK analysed the data and drafted the manuscript. SK conceived the study, contributed to the design and development of the manuscript. All authors read and approved the final manuscript.

\section{Acknowledgements}

This research was conducted at the Queensland Centre for Mothers \& Babies, an independent research centre located at the University of Queensland and funded by the Queensland Government. We would like to acknowledge the women who participated in the survey and to the 28 Aboriginal and/or Torres Strait Islander peer Interviewers who were fundamental to the success of the project. The authors would also like to acknowledge the contribution of the Queensland Centre for Mothers and Babies survey team, on which our survey was based. In particular, we would like to thank Yvette Miller and Samantha Prosser for their input into the design of the questionnaire used in the current study.

Received: 14 January 2014 Accepted: 28 April 2014

Published: 1 May 2014

\section{References}

1. Khalidi N, McGill K, Houweling H, Arnett K, Sheahan A: Closing the Gap in Low Birthweight Births between Indigenous and Non-Indigenous Mothers. QLD: Health Statistics Centre, Queensland Health; 2012.

2. AlHW: National Core Maternity Indicators Cat. no. PER 58. Canberra: National Perinatal Epidemiology and Statistics Unit; 2013.

3. Mantell CD, Craig ED, Stewart AW, Ekeroma AJ, Mitchell EA: Ethnicity and birth outcome: New Zealand trends 1980-2001: Part 2. Pregnancy outcomes for Maori women. Aust N Z J Obstet Gynaecol 2004, 44(6):537-540.

4. Hoy WE, Nicol JL: Birthweight and natural deaths in a remote Australian Aboriginal community. Med J Aust 2010, 192(1):14-19.

5. Johnston T, Coory M: Trends in perinatal mortality, birthweight and gestational age among Aboriginal, Torres Strait Islander and non-Indigenous babies in Queensland. In Information Circular No 67. Brisbane Epidemiology Services Unit, Health Information Branch, Queensland Health. ; 2004.

6. Kildea S: Risky business: contested knowledge over safe birthing services for Aboriginal women. Health Sociol Rev 2006, 15(4):387-396. 
7. Kruske S, Kildea S, Barclay L: Cultural safety and maternity care for Aboriginal and Torres Strait Islander Australians. Wom Birth 2006, 19(3):73-77.

8. Kruske S, Belton S, Wardaguga M, Narjic C: Growing up our way: the first year of life in remote Aboriginal Australia. Qual Health Res 2012, 22(6):777-787.

9. Carter B, Hussen E, Abbott L, Liddle M, Wighton M, McCormack M, Duncan P, Nathan P: Borning: Pmere Laltyeke Anwerne Ampe Mpwaretyeke, congress Alukura by the Grandmothers law. Aust Aboriginal Stud 1987, $1: 2-33$.

10. Hancock H: Aboriginal women's perinatal needs, experiences and maternity services: A literature review to enable considerations to be made about quality indicators. Ngaanyatjarra Health Service Literature Review 2006

11. Kildea S: And the women said... Report on birthing services for Aboriginal women from remote Top End communities. Darwin: Territory Health Services; 1999.

12. Dahlen H: Undone by fear? Deluded by trust? Midwifery 2010, 26(2):156-162

13. Australian Medical Association: Aboriginal and Torres Strait Islander Health Report Card 2012-2013: the healthy early years- getting the right start in life. available online at: https://ama.com.au/2012-13-ama-indigenoushealth-report-card-healthy-early-years-getting-right-start-life; 2013.

14. O'Driscoll T, Kelly L, Payne L, St Pierre-Hansen N, Cromarty H, Minty B, Linkewich B: Delivering away from home: the perinatal experiences of First Nations women in northwestern Ontario. Can J Rural Med 2011, 16(4):126-130.

15. Ireland S, Wulili Narjic C, Belton S, Kildea S: Niyith Nniyith Watmam (the quiet story): Exploring the experiences of Aboriginal women who give birth in their remote community. Midwifery 2011, 27(5):634-641.

16. Brownridge D: Understanding the elevated risk of partner violence against Aboriginal women: A comparison of two nationally representative surveys of Canada. J Fam Violence 2008, 23(5):353-367.

17. Kennedy B, Firman D: Indigenous SEIFA-Revealing the ecological fallacy. In Paper delivered at the 12th Biennial Conference of the Australian Population Association Australian Institute of Health and Welfare. Canberra: Australian Population Association; 2004.

18. Australian Bureau of Statistics: Demographic, Social and Economic Characteristics: Language, Culture and Socioeconomic Outcomes. In The Health and Welfare of Australia's Aboriginal and Torres Strait Islander Peoples, Oct 2010. Canberra: Catalogue 4704.0; 2010.

19. Health Q: Maternity and Newborn Services in Queensland Work Plan 2008-2012. Brisbane, QLD: Queensland Health; 2008.

20. Australian Health Ministers' Conference: National Maternity Services Plan: 2010. Canberra, ACT: Commonwealth of Australia; 2011

21. Queensland Health: Policy Directive: Clinical Governance for Midwifery Models of Care. Brisbane. Queensland; 2008.

22. Hirst C: Re-Birthing, Report of the Review of Maternity Services in Queensland. Brisbane: Qld Health; 2005.

23. Kildea S, Stapleton H, Murphy R, Low NB, Gibbons K: The Murri clinic: a comparative retrospective study of an antenatal clinic developed for Aboriginal and Torres Strait Islander women. BMC Pregnancy Childbirth 2012, 12(1):159.

24. Parker S, Kruske S: Make your voice heard: Having a baby in Queensland: Having a Baby in Queensland Aboriginal and Torres Strait Islander Survey. In Brisbane Australia: University of Queensland; 2012. http://www.qcmb.org.au/ aboriginal_and_torres_strait_islander_maternity_care_program/menu/ research_projects.

25. Prosser SJ, Miller YD, Armanasco A, Hennegan J, Porter J, Thompson R: Findings from the Having a Baby in Queensland Survey, 2012. Brisbane, QLD: Queensland Centre for Mothers \& Babies, The University of Queensland; 2013.

26. Glover K, Buckskin M, Ah Kit J, Miller R, Weetra D, Gartland D, Yelland J, Brown S: Antenatal care: experiences of Aboriginal women and families in South Australia. Preliminary Findings of the Aboriginal Families Study (April 2013). Adelaide, South Australia: Murdoch Childrens Research Institute, Melbourne, Victoria and Aboriginal Health Council of South Australia; 2013.

27. Queensland Department of Health: Perinatal Statistics Queensland 2011. Brisbane: Queensland Department of Health; 2013.

28. Li Z, Zeki R, Hilder L, Sullivan E: Australia's Mothers and Babies 2011. Perinatal Statistics Series No. 28. Cat. No. PER 59. Canberra: AlHW National Perinatal Epidemiology and Statistics Unit; 2013.

29. Australian Bureau of Statistics: Population Distribution, Aboriginal and Torres Strait Islander Australians 2006. Canberra: vol. Catalogue 4705.0; 2006.
30. Australian Institute of Health and Welfare and Australian Bureau of Statistics: The Health and Welfare of Australia's Aboriginal and Torres Strait Islander Peoples 2008. Canberra: vol. ABS cat no 4704.0; 2008.

31. Turrell G, Patterson C, Oldenburg B, Gould T, Roy M-A: The socio-economic patterning of survey participation and non-response error in a multilevel study of food purchasing behaviour: area- and individual-level characteristics. Publ Health Nutr 2003, 6(02):181-189.

32. Dowswell T, Carroli G, Duley L, Gates SGA, Khan-Neelofur D, Piaggio GGP: Alternative versus standard packages of antenatal care for low-risk pregnancy. In The Cochrane Collaboration, Volume 10. Belfast: The Cochrane Library; 2010.

33. Josif CM, Barclay L, Kruske S, Kildea S: 'No more strangers': Investigating the experiences of women, midwives and others during the establishment of a new model of maternity care for remote dwelling aboriginal women in northern Australia. Midwifery 2014, 30(3):317-323.

34. Homer CS, Foureur MJ, Allende T, Pekin F, Caplice S, Catling-Paull C: 'It's more than just having a baby' women's experiences of a maternity service for Australian Aboriginal and Torres Strait Islander families. Midwifery 2012, 28(4):E449-E455.

35. Dietsch E, Martin T, Shackleton P, Davies C, McLeod M, Alston M: Australian Aboriginal kinship: a means to enhance maternal well-being. Wom Birth 2011, 24(2):58-64.

36. McHugh AM, Hornbuckle J: Maternal and Child Health Model of Care in the Aboriginal Community Controlled Health Sector 2011. In Perth Aboriginal Health Council of Western Australia. 2011.

37. Nel P, Pashen D: Shared antenatal carefor Indigenous patientsin a rural and remote community. Aust Fam Physician 2003, 32(3):127-131.

38. Shipp J, Baker P, Wellings S: Literature Review Summary Report: Successful Strategies to Increase Involvement in Antenatal Care and to Increase Duration of Breastfeeding that Can Potentially be Applied to the Aboriginal and Torres Strait Islander Context. Rockhampton: Central Area Population Health Service, Queensland Health; 2006

39. Bar-Zeev S, Barclay L, Farrington C, Kildea S, V. WW: From hospital to home: the quality and safety of a postnatal discharge system used by remote dwelling Aboriginal women and their infants in the Top End of Australia. Midwifery 2012, 28:366-373.

40. DoHA: New Directions: Mothers and Babies Services Performance Audit Audit Report No.35 2011-12. Canberra: Commonwealth of Australia; 2012.

41. AHW: Healthy for Life: Results for July 2007-June 2011 Cat no. IHW 84. Canberra: Australian Institute of Health and Welfare; 2013.

42. DoHA: Stage 1 Evaluation of the Australian Nurse Family Partnership Program. Canberra: Ernest and Young; 2012.

43. Maputle S, Donavon HC: Woman-centred care in childbirth: A concept analysis (Part 1). Curatonis 2013, 36(1):1-8

44. Dietsch E, Shackleton P, Davies C, McLeod M, Alston M: 'You can drop dead': Midwives bullying women. Wom Birth 2010, 23(2):53-59.

45. Kildea S, Van Wagner V: 'Birthing on country,' maternity service delivery models: A review of the literature. In An Evidence Check rapid review brokered by the Sax Institute. Sydney: on behalf of the Maternity Services Inter-Jurisdictional Committee for the Australian Health Minister's Advisory Council; 2012. http://www.saxinstitute.org.au.

46. Fitzpatrick JM: Obstetric health services in Far North Queensland: is choice an option? Aust J Publ Health 1995, 19(6):580-588.

47. Fitzpatrick J: Birthing Choices in Far North Queensland. Brisbane: Department of Health, Housing and Community Service; 1993.

48. Chamberlain M, Barclay K,AK, Moyer A, Moyer A: Aboriginal birth psychosocial or physiological safety. Birth Issues 2001, 10(3):81-85.

49. Larkins S, Page P, Panaretto K, Robert Scott MRM, Valerie A, Craig Veitch P, Suzanne MG: Attitudes and behaviours of young Indigenous people in Townsville concerning relationships, sex and contraception: the "U Mob Yarn Up" project. Med J Aust 2007, 186(10):513-518.

50. Brown H, Varcoe C, Calam B: The birthing experiences of rural aboriginal women in context: implications for Nursing/Les experiences d'accouchement des femmes autochtones en region rurale, mises en contexte: les implications en matiere de soins infirmiers. Can J Nurs Res 2011, 43(4):100-117.

51. ABS: Australian Social Trends, 2004 Income Distribution: Incomes of Aboriginal and Torres Strait Islander Australians, Volume 4102.0. Canberra: Australian Bureau of Statistics; 2004

52. Gosden A: A report on the Development of a Midwifery Model of care for the Joyce Palmer Health Service (Palm Island). Townsville: Townsville Health Service District, Queensland Health; 2008. 
53. Callister LC, Holt ST, Kuhre MW: Giving birth: the voices of Australian women. J Perinat Neonatal Nurs 2010, 24(2):128-136.

54. Kildea S, Van Wagner V: 'Birthing on country,' maternity service delivery models: A review of the literature. In An Evidence Check Rapid Review Brokered by the Sax Institute. Sydney: Maternity Services Inter-Jurisdictional Committee for the Australian Health Minister's Advisory Council: Canberra; 2012

55. Dudgeon $P$, Wright $M$, Coffin J: Talking it and walking it: cultural competence. J Aust Indigenous Issues 2010, 13(3):29-44.

56. Anonymous: Birthing on country. Queens/ Nurse 2011, 30(3):34.

57. Kildea S, Kruske S, Barclay L, Tracy S: 'Closing the Gap': how maternity services can contribute to reducing poor maternal infant health outcomes for Aboriginal and Torres Strait Islander women. Rural Rem Health 2010, 10(3):1383

58. Johnstone K,AE: Fertility and the demography of Indigenous Australians: What can the NATSISS 2008 tell us? In Understanding Indigenous disadvantage: Social science perspectives on the 2008 National Aboriginal and Torres Strait Islander Social Survey. Edited by Hunter B, Biddle N. Canberra: ANU E-Press; 2012

59. Brown SJ, Weetra D: Aboriginal Families Study: Policy Brief 2. Melbourne: Murdoch Childrens Research Institute; 2013.

60. Kruske S: The Characteristics of Culturally Competent Maternity Care for Aboriginal and Torres Strait Islander Women. Canberra: Maternity Services Inter-jurisdictional Committee for the Australian Health Ministers' Advisory Council; 2011

61. Homer C, Foureur M, Allende T, Pekin F, Caplice S, Catling-Paull C: 'It's more than just having a baby' women's experiences of a maternity service for Australian Aboriginal and Torres Strait Islander families. Midwifery 2012, 28(4):e509-e515.

62. Gao Y, Gold L, Josif C, Bar-Zeev S, Steenkamp M, Barclay L, Zhao Y, Tracy S, Kildea S: A cost-consequences analysis of a midwifery group practice for aboriginal mothers and infants in the top end of the northern territory, Australia. Midwifery 2014, 30(4):447-455

63. Arnold J, De Costa C, Howat P: Timing of transfer for pregnant women from Queensland Cape York communities to Cairns for birthing. Med J Aust 2009, 190(10):594-596.

64. Tracy SK, Hartz DL, Tracy MB, Allen J, Forti A, Hall B, White J, Lainchbury A, Stapleton H, Beckmann M, Bisits A, Homer C, Foureur M, Welsh A, Kildea S: Caseload midwifery care versus standard maternity care for women of any risk: M@NGO, a randomised controlled trial. Lancet 2013, 382 (9906):1723-1932. doi:10.1016/S0140-6736(13)61406-3.

65. Brown S, Lumley J: Changing childbirth: lessons from an Australian survey of 1336 women. Br J Obstet Gynaecol 1998, 105(2):143-155.

66. O'Brien B, Chalmers B, Fell D, Heaman M, Darling EK, Herbert P: The experience of pregnancy and birth with midwives: Results from the Canadian Maternity Experiences Survey. Birth 2011, 38(3):207-215.

67. Sandall J, Soltani H, Gates S, Shennan A, Devane D: Midwife-led continuity models versus other models of care for childbearing women. Cochrane Database Syst Rev 2013, 8(8):CD004667.

68. Geia L: First Steps, Making Footprints: Intergenerational Palm Island Families' Indigenous Stories (narratives) of Childrearing Practice Strengths, PhD thesis. Townsville: James Cook University; 2012.

69. Geia LK, Hayes B, Usher K: A strengths based approach to Australian Aboriginal childrearing practices is the answer to better outcomes in Aboriginal family and child health. Collegian 2011, 18(3):99-100.

70. Ivanova V, Brown J: Strengths of aboriginal foster parents. J Child Fam Stud 2011, 20(3):279-285

71. Iwasaki Y, Bartlett JG, Gottlieb B, Hall D: Leisure-like pursuits as an expression of aboriginal cultural strengths and living actions. Leisure Sci 2009 31(2):158-173.

72. Kruske S, Belton S, Wadaguga M, Narjic C: Growing up our way: the first year of life in remote Aboriginal Australia. Qual Health Rev 2012, 22(6):777-787.

73. Priest N, Mackean T, Davis E, Waters E, Briggs L: Strengths and challenges for Koori kids: Harder for Koori kids, Koori kids doing well-Exploring Aboriginal perspectives on social determinants of Aboriginal child health and wellbeing. Health Sociol Rev 2012, 21(2):165-179.

74. Darbyshire $P$, Jackson D: Using a strengths approach to understanding resilience and build health capacity in families. Contemp Nurse 2004 18(1-2):211-212

75. Scougall J: Occasional Paper 19. Lessons Learnt about Strengthening Indigenous Families and Communities: Stronger Families and Communities Strategy 2000-2004. Canberra: ACT: FaCHSIA; 2008.
76. Buckskin M, Ah Kit J, Glover K, Mitchell A, Miller R, Weetra D, Wiebe J, Yelland JS, Newbury J, Robinson J, Brown SJ: Aboriginal families study: a population-based study keeping community and policy goals in mind right from the start. Int J Equity Health 2013, 12(1):41.

77. Herceg A: Improving Health in Aboriginal and Torres Strait Islander mothers, Babies and Young Children: A Literature Review. Canberra: Australian Government Department of Health and Ageing; 2005.

78. Rumbold A, Cunningham J: A review of the impact of antenatal care services for Australian Indigenous women and attempts to strengthen these services. Matern Child Health J 2008, 12(1):83-100.

79. Panaretto $K$, Lee $H$, Mitchell M, Larkins S, Manessis V, Buettner $P$, Watson D: Risk factors for preterm, low birth weight and small for gestational age birth in urban Aboriginal and Torres Strait Islander women in Townsville. Aust N Z J Public Health 2006, 30(2):163-170.

80. Panaretto KS, Lee HM, Mitchell MR, Larkins SL, Manessis V, Buettner PG, Watson D: Prevalence of sexually transmitted infections in pregnant urban Aboriginal and Torres Strait Islander women in northern Australia. Aust N Z J Obstet Gynecol 2006, 46(3):217-224.

81. Powell J, Dugdale AE: Obstetric outcomes in an Aboriginal community: a comparison with the surrounding rural area. Aust J Rural Health 1999, 7(1):13-17.

doi:10.1186/1472-6963-14-196

Cite this article as: Parker et al:: 'Choice, culture and confidence': key findings from the 2012 having a baby in Queensland Aboriginal and Torres Strait Islander survey. BMC Health Services Research 2014 14:196.

\section{Submit your next manuscript to BioMed Central and take full advantage of:}

- Convenient online submission

- Thorough peer review

- No space constraints or color figure charges

- Immediate publication on acceptance

- Inclusion in PubMed, CAS, Scopus and Google Scholar

- Research which is freely available for redistribution

Submit your manuscript at www.biomedcentral.com/submit
C) Biomed Central 